\title{
Modelling Circumpolar Deep Water intrusions on the Amundsen Sea continental shelf, Antarctica
}

\author{
Malte Thoma, ${ }^{1,2}$ Adrian Jenkins, ${ }^{1}$ David Holland, ${ }^{3}$ and Stan Jacobs ${ }^{4}$ \\ Received 6 June 2008; revised 17 July 2008; accepted 7 August 2008; published 18 September 2008.
}

[1] Results are presented from an isopycnic coordinate model of ocean circulation in the Amundsen Sea, focusing on the delivery of Circumpolar Deep Water (CDW) to the inner continental shelf around Pine Island Bay. The warmest waters to reach this region are channeled through a submarine trough, accessed via bathymetric irregularities along the shelf break. Temporal variability in the influx of CDW is related to regional wind forcing. Easterly winds over the shelf edge change to westerlies when the Amundsen Sea Low migrates west and south in winter/spring. This drives seasonal on-shelf flow, while inter-annual changes in the wind forcing lead to inflow variability on a decadal timescale. A modelled period of warming following low CDW influx in the late 1980's and early 1990's coincides with a period of observed thinning and acceleration of Pine Island Glacier. Citation: Thoma, M., A. Jenkins, D. Holland, and S. Jacobs (2008), Modelling Circumpolar Deep Water intrusions on the Amundsen Sea continental shelf, Antarctica, Geophys. Res. Lett., 35, L18602, doi:10.1029/2008GL034939.

\section{Introduction}

[2] The West Antarctic Ice Sheet has been losing mass to the oceans at an accelerating rate over recent decades [Rignot et al., 2008]. The most significant losses have been focused in a few key catchment basins that drain across the Amundsen Sea coastline, where dynamical changes in the outlet glaciers have led to increased discharge. The synchronous response of several independent glaciers, coupled with rapid thinning of their floating termini [Shepherd et al., 2004], is generally taken as an indicator that the changes are being forced by the ocean. The assumption is that a warming of the waters on the Amundsen Sea continental shelf has led to an increase in the rate of melting at the base of the floating ice shelves. The resultant thinning of the ice shelves has reduced the longitudinal stresses transmitted upstream allowing more rapid ice flow.

[3] Jacobs et al. [1996] reported deep flooding of the Amundsen Sea continental shelf by almost unmodified $\left(\sim 1^{\circ} \mathrm{C}\right)$ Circumpolar Deep Water $(\mathrm{CDW})$, which flows beneath the ice shelves, and was shown to drive rapid melting of the floating terminus of Pine Island Glacier

\footnotetext{
${ }^{1}$ British Antarctic Survey, Natural Environment Research Council, Cambridge, UK.

${ }^{2}$ Now at Alfred Wegener Institute for Polar and Marine Research, Bremerhaven, Germany.

${ }^{3}$ Courant Institute of Mathematical Sciences, New York University, New York, New York, USA.

${ }^{4}$ Lamont-Doherty Earth Observatory, Columbia University, Palisades, New York, USA.

Copyright 2008 by the American Geophysical Union. 0094-8276/08/2008GL034939\$05.00
}

(PIG). Evidence for shelf water variability comes from reoccupied ocean stations that show, for example, slightly cooler and fresher waters in 2000 than in 1994 [Jacobs, 2006]. Bathymetric soundings compiled by Nitsche et al. [2007] reveal a series of deep inner shelf troughs extending seaward from the main outlet glaciers (Figure 1). The main trough leading north from greater Pine Island Bay (PIB) bifurcates on the outer shelf and shoals to sills, which then dip northward to shelf break depths $>600 \mathrm{~m}$ near $103^{\circ}$ and $113^{\circ} \mathrm{W}$. Walker et al. [2007] used oceanographic measurements to infer significant on-shelf flow of CDW near the latter site. This study uses a numerical model to investigate the forcing and temporal variability of that inflow and its significance for the water properties in PIB.

\section{Model}

[4] We use a version of the Miami Isopycnic Coordinate Ocean Model [Bleck et al., 1992] adapted to include subice-shelf cavities [Holland and Jenkins, 2001] and coupled with a simple sea ice model [Holland, 2001]. The coupled model is forced with daily mean surface air temperature and sea level pressure from the NCEP/NCAR reanalysis [Kalnay et al., 1996]. The domain (Figure 1) is discretised using an isotropic grid with a horizontal resolution ranging from $13.5 \mathrm{~km}$ in the south to $28 \mathrm{~km}$ in the north. Vertical discretisation is achieved using a surface mixed layer (layer 1) with a freely evolving density and 10 isopycnic layers with densities chosen such that layers 2-6 represent the main thermocline, layers 7-8 CDW, and layers 9-11 the transition to Antarctic Bottom Water. Initial conditions are derived from Olbers et al. [1992], data that also provide eastern, western and northern boundary conditions, applied throughout the integration by relaxation of the outer three rows of grid cells using time constants of 10-30 days. Artefacts were apparent in the circulation near boundaries, but the impacts did not spread to the domain interior. Sensitivity studies with relocated lateral boundaries reproduced the key features of the solution discussed below. Initial and boundary conditions for the sea ice model rely on a Cavalieri et al. [1997] ice concentration climatology, and an assumed thickness of $1 \mathrm{~m}$. The model is spun up for 10 years, using atmospheric data from 1979 in a repeating cycle, then run from 1980 to the end of 2004. The bathymetric grid was formed by blending the BEDMAP bed elevation grid [Lythe et al., 2001] with an earlier version of the Nitsche et al. [2007] compilation that included all data collected prior to 2006.

\section{Results}

[5] The densest and warmest waters to access the deep troughs of the eastern Amundsen shelf correspond to layers 

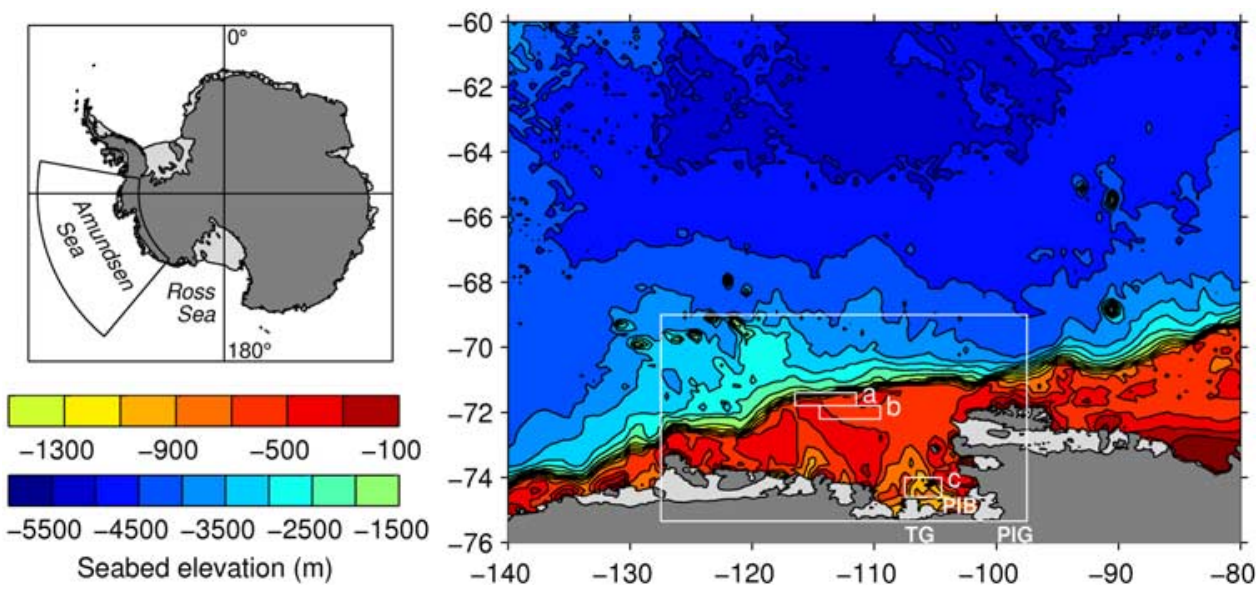

Figure 1. (right) Seabed elevation over (left) the region considered in this study. The large white box indicates the coverage of Figure 2, while the smaller, labelled boxes are the study areas used in Figure 3. Dark (light) grey shading indicates grounded (floating) ice. Labels identify Pine Island Bay (PIB), Pine Island Glacier (PIG) and Thwaites Glacier (TG).

7 and 8. These waters appear to move onto the shelf near $113^{\circ} \mathrm{W}$, and then flow to the east and south to reach the inner shelf (Figure 2). There is a seasonal pulsing of the inflow, which is strongest during the winter and spring, and marked inter-annual variability in the layer thickness on shelf, dependent on the strength of the winter/spring input.
CDW layer thickness near the shelf edge also differs markedly (Figure 2), and that determines the depth of its upper surface relative to the shelf break and hence the thickness of the CDW intrusion onto the shelf.

[6] A coherent seasonal cycle is apparent below layer 4 in the layer interfaces over the upper continental slope
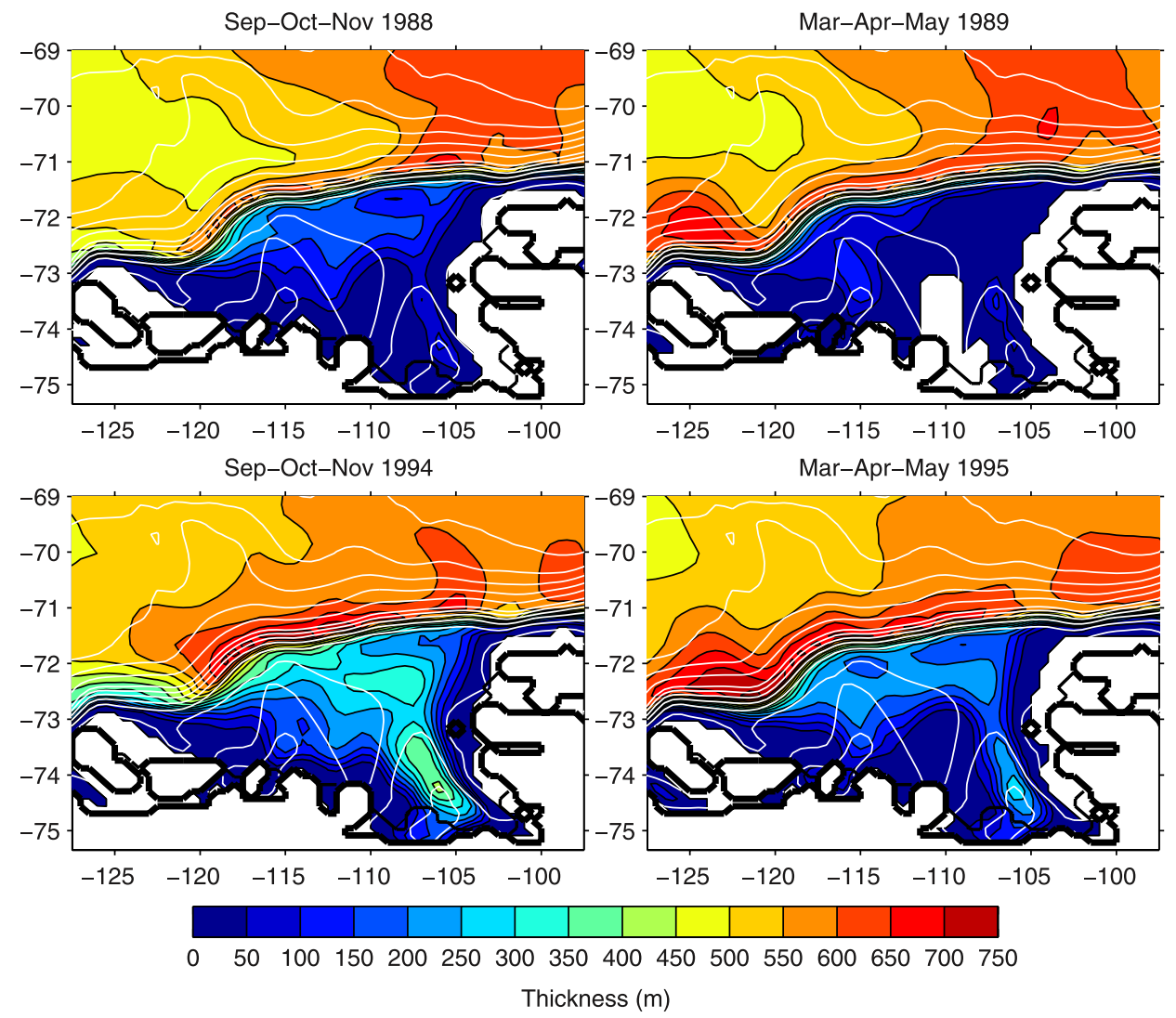

Figure 2. Combined thickness of layers 7 and 8 averaged through the spring and autumn of two contrasting years over the area indicated in Figure 1. Heavy black lines indicate the grounding line, while light black lines show the ice fronts. White lines are contours of seabed depth (at $200 \mathrm{~m}$ intervals from 100 to $1500 \mathrm{~m}$, and $500 \mathrm{~m}$ intervals thereafter). 

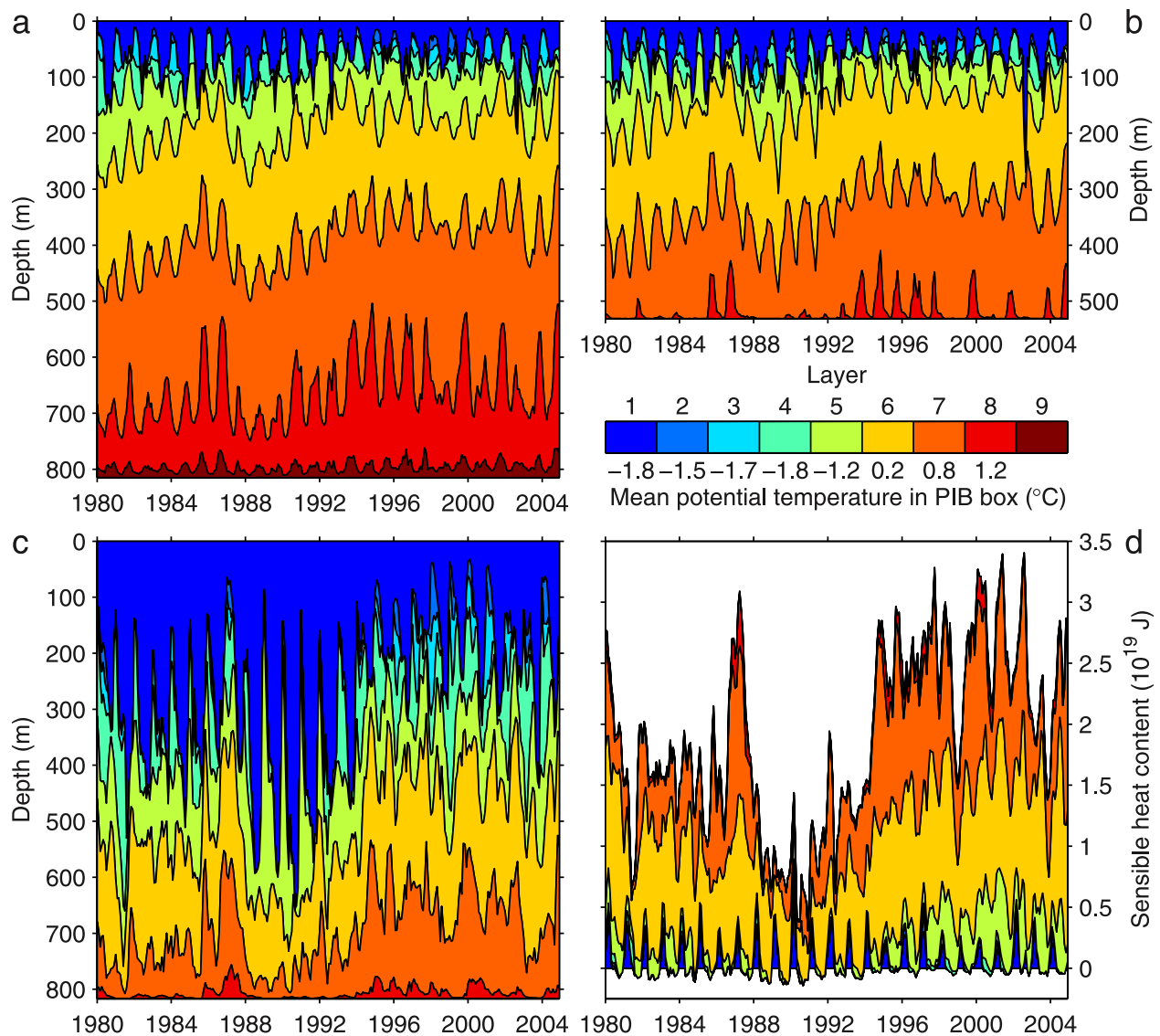

Figure 3. Time series of average layer thickness over the (a) upper slope, (b) outer shelf and (c) inner shelf regions indicated by the small boxes in Figure 1. (d) Layerwise cumulative sensible heat content, relative to the surface freezing point, of the inner shelf region. Average temperatures of layers in Figures $3 \mathrm{c}$ and $3 \mathrm{~d}$ are indicated below the legend.

(Figure 3a). The largest thickness changes occur in layer 8 , the top of which usually lies just below the shelf break (Figure 3b). Variability in the amplitude of the seasonal cycle gives rise to the intermittent appearance of layer 8 on the outer shelf (Figure $3 \mathrm{~b}$ ) and this signal, slightly smoothed, propagates to the inner shelf (Figure 3c) with a delay of a few months. Layer 7 has more widespread access to the shelf, with inflows that are not confined to the trough, but its thickness and lateral extent are roughly coherent with the layers above and below. Variation in the mixed layer (layer 1) depth is the dominant feature of Figure 3c, but most of the heat is contained in the deeper layers. Figure $3 \mathrm{~d}$ is thus dominated by variability associated with CDW inflows from the shelf edge. The total heat content of the water column was at a minimum in the late 1980's and early 1990's when layers 7 and 8 occupied a much smaller fraction of the PIB study area.

[7] We investigated temporal correlations of the CDW layer thickness between the three study areas of Figure 3 on seasonal and longer timescales. For the mean annual cycles of the layer 6/7 interface height, the highest correlation (99\% confidence interval) between the upper continental slope and shelf edge was $0.97(0.83-0.99)$ at zero lag, and between the shelf edge and inner shelf was $0.87(0.44-$ 0.98 ) at 1 month lag. With a 12-month low pass filter applied to the layer $6 / 7$ interface heights, highest correla- tions were, respectively, $0.97(0.96-0.98)$ at 1 month lag and $0.78(0.72-0.83)$ at 2 months lag.

[8] Comparison with the limited observational database reveals both strengths and weaknesses in the model results. Inflow of CDW near $113^{\circ} \mathrm{W}$ agrees with the inferences of Walker et al. [2007], although their measurements were made at a time of year when the modelled inflow is weak. On the inner shelf (Figure 3d) the model's summer of 2000 is warmer than that of 1994, at odds with the observations. However, the modelled variability is intimately linked with the NCEP-derived forcing, which is poorly constrained by data in this region, and the model response can highlight processes by which regional atmospheric variability may drive water mass variability on the inner continental shelf. The on-shelf variability is highly correlated with nearbottom conditions on the upper continental slope, well below the maximum depth of the surface mixed layer. Our hypothesis that this variability is caused by the interaction of a time-varying, wind-forced circulation with the bathymetry is supported by sensitivity studies, forced with constant winds, where little shelf-slope exchange occurs beneath the surface layers.

\section{Forcing}

[9] Seasonal averages of the daily pressure fields used to derive the geostrophic winds applied to the model are 

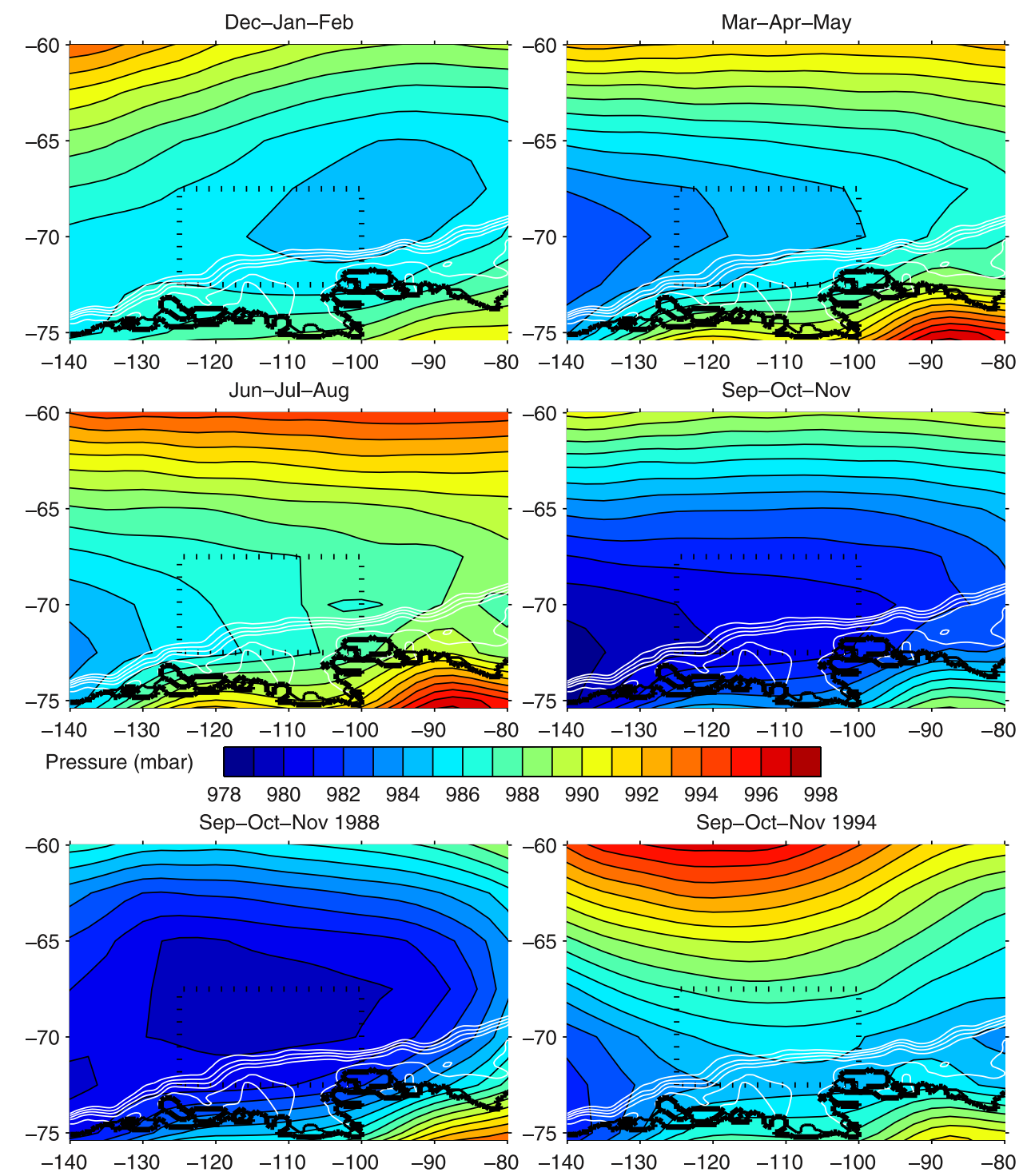

Figure 4. (top) Mean seasonal pressure fields over the model domain for the 1980 to 2004 period and (bottom) springtime means for 1988 and 1994. The box outlined by the heavy dotted line is used to define the north-south pressure index discussed in the text. Heavy black lines indicate the grounding line, while light black lines show the ice fronts. White lines are contours of seabed depth (at $500 \mathrm{~m}$ intervals from 500 to $2500 \mathrm{~m}$ ).

dominated by the Amundsen Sea Low, which shifts to the west and south in winter and spring (Figure 4). This shift in the pressure field is a combination of the annual longitudinal migration of the centre of the climatological low [Simmonds and King, 2004] and the biannual contraction of the circumpolar pressure trough associated with the semiannual oscillation [van den Broeke, 2000]. During summer and autumn the band of easterly winds to the south of the pressure trough within the model drives a westward current over the continental shelf and slope. The southward shift of the pressure trough later in the year then brings a core of eastward currents onto the continental slope. By late winter westerly winds occur over the outer shelf and slope, especially east of $130^{\circ} \mathrm{W}$, and dense waters move up onto the shelf and eastward towards the main trough leading to PIB (Figure 2). Physical processes that could cause these incursions include the interaction of eddies with the mean flow over the sloping bathymetry [Adcock and Marshall, 2000], shear induced in the along-slope flow during periods of westerly winds [Johnson and Rockliff, 1986], interaction of variable slope currents with the shelf-edge irregularities [Klinck, 1996; Dinniman and Klinck, 2004] and Ekman transport of surface waters off the shelf. It is practically impossible to distinguish the relative importance of such mechanisms in a model where key processes are subsumed into the sub-grid scale parameterisations.

[10] To characterise the variable forcing on the outer shelf and slope we define a westerly geostrophic wind index as the mean north to south pressure difference over the box marked in Figure 4. For the mean annual cycles, the highest correlation ( $99 \%$ confidence interval) between the pressure index and the height of the layer 6/7 interface over the upper slope (Figure 3a) is $0.90(0.57-0.98)$ at zero lag, while for the 12-month low pass filtered signals it is $0.59(0.48-0.68)$ 
also at zero lag. The implication is that periods of stronger westerly winds correspond to times when the shelf receives a larger inflow of CDW. Contrasting the mean pressure field over the spring seasons of 1988 and 1994 (Figure 4) shows the Amundsen Sea Low farther west and south in 1994, coincident with westerly winds over the outer shelf and a stronger inflow (Figure 2).

\section{Discussion and Conclusions}

[11] An isopycnic coordinate model of ocean circulation in the Amundsen Sea, forced by the NCEP/NCAR reanalysis, displays temporal and spatial variability in the delivery of CDW to PIB. Although the results do not match some details of the oceanographic measurements, they are broadly consistent with observations and modelling of shelf-slope exchange in other regions. It is thus worth comparing the simulated water column heat content on the inner shelf (Figure 3d) with observed glaciological change in the region. The widespread glacier thinning observed by Shepherd et al. [2004] between 1992 and 2001 coincided with near-continuous warming in the model. Rignot [1998, 2001] reported retreat of the PIG and Thwaites Glacier grounding lines over the early part of this period (1992-96) when the modelled warming was most rapid. Joughin et al. [2003] show that the post-1974 acceleration of PIG was interrupted by a period of nearly steady flow from at least 1987 to 1994 . These dates bracket the modelled period of weakest inflow to the shelf and lowest water column heat content. During the 1994 to 2000 acceleration, the largest changes occurred after 1996 [Joughin et al., 2003], the warmest period in the model results. If realistic, the modelled fluctuation in CDW input to PIB is thus a candidate for driving the observed glaciological changes.

[12] The Amundsen Sea is renowned as a centre of high atmospheric variability, influenced by, for example, the Southern Annular Mode (SAM) and a strong El NiñoSouthern Oscillation (ENSO) teleconnection. Fogt and Bromwich [2006] describe decadal variability in the far south Pacific atmospheric circulation dictated by different phasing of SAM and ENSO in the 1980's and 1990's. The complex interaction of these large-scale modes of variability may explain a low correlation between our local north-south pressure index and the SAM and ENSO indices. Nonetheless, a decade of generally falling shelf water heat content in the 1980's followed by a decade of warming in the 1990's (Figure 3d) would generate a complex response in the ice streams, where dynamically-induced thickness changes have been shown to propagate inland on a similar timescale [Payne et al., 2004]. This exacerbates the problem of inferring long-term trends in ice sheet mass balance from relatively short records of ice velocity and thickness change.

[13] Our model setup excludes some processes that could conceivably influence shelf water temperatures, such as hydrodynamic instability in the Antarctic Circumpolar Current, variability in the transport of the Ross Gyre [Assmann and Timmermann, 2005] or changes in CDW properties. However, the most active cores of the ACC lie well north of the shelf break in this region [Orsi et al., 1995], and most southward transport of the Ross Gyre probably occurs to the west of our domain. In addition, variations in CDW core temperature must clear the shelf-edge barrier by some mechanism, and then survive cross-shelf transport in order to influence the floating ice cover. While warming air temperatures may take centuries to substantially change CDW core properties, the control of CDW flow to the inner shelf by regional wind forcing means that atmospheric circulation changes can alter the heat content of the waters deep in PIB on sub-annual timescales. This implies a complex spectrum of forcing on the ice sheet, and highlights the need to understand how that forcing might change in the future in order to make predictions of ice sheet evolution.

[14] Acknowledgments. This work was supported by the Natural Environment Research Council's Autosub Under Ice Thematic Programme (NER/T/S/2000/00987) and by the National Science Foundation (ANT0732869 and ANT-0440775). NCEP Reanalysis data were provided by the NOAA/OAR/ESRL PSD, Boulder, Colorado, USA, from their Web site at http://www.cdc.noaa.gov/. We thank two anonymous reviewers for constructive comments.

\section{References}

Adcock, S. T., and D. P. Marshall (2000), Interactions between geostrophic eddies and the mean circulation over large-scale bottom topography, J. Phys. Oceanogr., 30(12), 3223-3238.

Assmann, K. M., and R. Timmermann (2005), Variability of dense water formation in the Ross Sea, Ocean Dyn., 55(2), 68-87, doi:10.1007/ s10236-004-0106-7.

Bleck, R., C. Rooth, D. Hu, and L. T. Smith (1992), Salinity-driven thermocline transients in a wind- and thermohaline-forced isopycnic coordinate model of the North Atlantic, J. Phys. Oceanogr., 22(12), 1486-1505.

Cavalieri, D. J., C. L. Parkinson, P. Gloersen, and H. J. Zwally (1997), Arctic and Antarctic sea ice concentrations from multichannel passivemicrowave satellite data sets: October 1978-September 1995, user's guide, NASA Tech. Memo., 104647, 17 pp.

Dinniman, M. S., and J. M. Klinck (2004), A model study of circulation and cross-shelf exchange on the west Antarctic Peninsula continental shelf, Deep Sea Res., Part II, 51(17-19), 2003-2022, doi:10.1016/ j.dsr2.2004.07.030.

Fogt, R. L., and D. H. Bromwich (2006), Decadal variability of the ENSO teleconnection to the high latitude South Pacific governed by coupling with the Southern Annular Mode, J. Clim., 19(6), 979-997.

Holland, D. M. (2001), Transient sea-ice polynya forced by environmental flow variability, Prog. Oceanogr., 48(4), 475-532.

Holland, D. M., and A. Jenkins (2001), Adaptation of an isopycnic coordinate ocean model for the study of circulation beneath ice shelves, Mon. Weather Rev., 129(8), 1905-1927.

Jacobs, S. (2006), Observations of change in the Southern Ocean, Philos. Trans. R. Soc. A, 364(1844), 1657-1681, doi:10.1098/rsta.2006.1794.

Jacobs, S. S., H. H. Hellmer, and A. Jenkins (1996), Antarctic ice sheet melting in the southeast Pacific, Geophys. Res. Lett., 23(9), 957-960.

Johnson, J. A., and N. Rockliff (1986), Shelf break circulation processes, in Baroclinic Processes on Continental Shelves, Coastal Estuarine Sci., vol. 3, edited by C. N. K. Mooers, pp. 33-62, AGU, Washington, D. C.

Joughin, I., E. Rignot, C. E. Rosanova, B. K. Lucchitta, and J. Bohlander (2003), Timing of recent accelerations of Pine Island Glacier, Antarctica, Geophys. Res. Lett., 30(13), 1706, doi:10.1029/2003GL017609.

Kalnay, E., et al. (1996), The NCEP/NCAR 40-year reanalysis project, Bull. Am. Meteorol. Soc., 77(3), 437-471.

Klinck, J. M. (1996), Circulation near submarine canyons: A modeling study, J. Geophys. Res., 101(C1), 1211-1223.

Lythe, M. B., D. G. Vaughan, and the BEDMAP Consortium (2001), BEDMAP: A new ice thickness and subglacial topographic model of Antarctica, J. Geophys. Res., 106(B6), 11,335-11,351.

Nitsche, F. O., S. S. Jacobs, R. D. Larter, and K. Gohl (2007), Bathymetry of the Amundsen Sea continental shelf: Implications for geology, oceanography, and glaciology, Geochem. Geophys. Geosyst., 8, Q10009, doi:10.1029/2007GC001694.

Olbers, D., V. Gouretzki, G. Seiss, and J. Schröter (1992), The hydrographic atlas of the Southern Ocean, Alfred-Wegener-Inst., Bremerhaven, Germany. (Available at http://store.pangaea.de/documentation/sodb/)

Orsi, A. H., T. Whitworth III, and W. D. Nowlin Jr. (1995), On the meridional extent and fronts of the Antarctic Circumpolar Current, Deep Sea Res., Part I, 42(5), 641-673.

Payne, A. J., A. Vieli, A. P. Shepherd, D. J. Wingham, and E. Rignot (2004), Recent dramatic thinning of largest West Antarctic ice stream triggered by oceans, Geophys. Res. Lett., 31, L23401, doi:10.1029/ 2004 GL021284. 
Rignot, E. J. (1998), Fast recession of a West Antarctic glacier, Science, 281(5376), 549-551, doi:10.1126/science.281.5376.549.

Rignot, E. (2001), Evidence for rapid retreat and mass loss of Thwaites Glacier, West Antarctica, J. Glaciol., 47(157), 213-222.

Rignot, E., J. L. Bamber, M. R. van den Broeke, C. Davis, Y. Li, W. J. van den Berg, and E. Meijgaard (2008), Recent Antarctic ice mass loss from radar interferometry and regional climate modelling, Nat. Geosci., 1(2), 106-110, doi:10.1038/ngeo102.

Shepherd, A., D. Wingham, and E. Rignot (2004), Warm ocean is eroding West Antarctic Ice Sheet, Geophys. Res. Lett., 31, L23402, doi:10.1029/ 2004 GL021106.

Simmonds, I., and J. C. King (2004), Global and hemispheric climate variations affecting the Southern Ocean, Antarct. Sci., 16(4), 401-413, doi:10.1017/S0954102004002226.

van den Broeke, M. (2000), The semi-annual oscillation and Antarctic climate. Part 4: A note on sea ice cover in the Amundsen and Bellingshausen seas, Int. J. Climatol., 20(4), 455-462.
Walker, D. P., M. A. Brandon, A. Jenkins, J. T. Allen, J. A. Dowdeswell, and J. Evans (2007), Oceanic heat transport onto the Amundsen Sea shelf through a submarine glacial trough, Geophys. Res. Lett., 34, L02602, doi:10.1029/2006GL028154.

D. Holland, Courant Institute of Mathematical Sciences, New York University, New York, NY 10012, USA

S. Jacobs, Lamont-Doherty Earth Observatory, Columbia University, Palisades, NY 10694, USA.

A. Jenkins, British Antarctic Survey, Natural Environment Research Council, Cambridge CB3 0ET, UK. (ajen@bas.ac.uk)

M. Thoma, Alfred Wegener Institute for Polar and Marine Research, D-27515 Bremerhaven, Germany. 